\title{
Adams Oliver sendromlu bir yenidoğan: Bir olgu sunumu ve literatür değerlendirmesi
}

\section{A neonate with Adams Oliver syndrome: A case report and review of the literature}

\section{Hande Küçük Kurtulgan*, Fatih Bolat, Gülseren Erkoca Göktolga, Nejmiye Akkuş, Şenol Çitli, İlhan Sezgin}

Tıbbi Genetik Anabilim Dalı (Dr. H. Küçük Kurtulgan, Dr. G. Erkoca Göktolga, Dr. N. Akkuş, Dr. Ş. Çitli, Prof. Dr. İ. Sezgin), Çocuk Sağlı̆̆ı ve Hastalıkları Anabilim Dalı (Yrd. Doç. Dr. F. Bolat), Cumhuriyet Üniversitesi Tıp Fakültesi, TR-58140 Sivas

\section{Özet}

Adams Oliver Sendromu ilk defa 1945 yılında Adams ve Oliver tarafından tanımlanmıştır. Aplasia kutis konjenitale ve değişik derecede transvers ekstremite defektleri ile karakterize bir sendromdur. Bir günlük kız bebek aplazi kutis konjenita ve ekstremite defekti ile yenidoğan yoğun bakım ünitemize yatırıldı. Tanısı klinik özellikleri ve radyolojik bulgular ile konuldu. Bu olgu sunumunda biz, Adams Oliver sendromlu bir vaka sunduk ve literatürde bildirilen Adams Oliver sendromlu olguların klinik özelliklerini tartıştık.

Anahtar sözcükler: Adams Oliver sendromu, aplazi kutis konjenita, klinik özellikler; ekstremite defektleri

\begin{abstract}
Adams Oliver syndrome was first described by Adams and Oliver in 1945. It is a syndrome characterized by aplasia cutis congenita and terminal transverse limb defects of variable severity. A one-day-old female neonate was admitted to the neonatal intensive care unit with aplasia cutis congenita and limb defects. The diagnosis of Adams Oliver syndrome was based on the typical disease features, together with typical appearances on radiography. In this case report, we present a case diagnosed with Adams Oliver syndrome and we also discuss the clinical findings of patients with Adams Oliver syndrome reported in the literature.
\end{abstract}

Keywords: Adams Oliver syndrome, aplasia cutis congenita, clinical features, limb defects

Geliş tarihi/Received: 17 Ekim 2012; Kabul tarihi/Accepted: 18 Ekim 2012

*İletişim adresi:

Dr. Hande Küçük Kurtulgan, Tıbbi Genetik Anabilim Dalı, Cumhuriyet Üniversitesi Tıp Fakültesi TR-58140 Sivas. E-posta: drhandekucuk@yahoo.com.tr

\section{Giriş}

Adams Oliver Sendromu 1945 yılında Adams ve Oliver tarafindan tanımlanan; aplazi kutis konjenita ve transvers ekstremite defektleri ile karakterize bir sendromdur [1]. Sendromun ilk tanımlandığında otozomal dominant geçişli olduğu belirtilmesine rağmen daha sonraları otozomal resesif ve sporadik formları bildirilmiştir. Prevalansı tam olarak bilinmemektedir. Etiyolojisi tam olarak aydınlatılmamış olmasına rağmen, patogenezinde embriyonel dönemde dolaşım bozukluğunun sonucu olabileceği öne sürülmüştür [2]. Vasküler anormal oluşuma neden olan primer defektin anormal vaskülogenezle ilişkili olduğu bildirilmektedir. İlk vaka tanımlanmasından itibaren değişik klinik bulgular ile birlikte olan vakalar bildirilmiştir. Bazı olgularda santral sinir sistemi, gastrointestinal sistem ve genitoüriner sistem anomalileri eşlik edebilir. İç organ anomalilerinin eşlik ettiği durumlarda ağır ve ölümcül seyredebilir [3]. 
$\mathrm{Bu}$ olgu sunumundaki amacımız Adams Oliver Sendromunun tipik klinik bulgularını tanımlayarak, konu literatür eşliğinde güncel verilerin tartışılmasıdır.

\section{Olgu sunumu}

Bir günlük iken görülen yenidoğan kız bebek, sağlıklı anne ve babanın birinci çocuğu olarak sorunsuz ve takipli bir gebelik sonrasında 39. gebelik haftasında normal spontan doğum ile 2850 gr ağırlığında hastanemizde doğdu. Anne baba arasında akrabalık ve ailede herhangi bir hastalık öyküsü belirlenemedi. Gebelik süresince anne herhangi bir teratojen ajan ile karşılaşmamış, enfeksiyon geçirmemiş ve rutin obstetrik ultrasonografik incelemeleri normal olarak saptanmıştı. Fizik muayene bulgularında; ağırlık: 2850 gr (1025p), boy: $46 \mathrm{~cm}(3 p)$, baş çevresi: $32 \mathrm{~cm}(3 p)$ olarak ölçüldü. Doğumdan sonra yapılan inspeksiyonda, $10 \times 10 \mathrm{~cm}$ boyutlarında, anterior fontanelden başlayıp posterior fontanele kadar uzanan nekrotik kenarlı cilt ve ciltaltı dokuyu da içine alan saçlı deri defekti görüldü. Bilateral el ve ayaklarda tırnak hipoplazisi ile distal falanks yokluğu ve kutis marmorata telenjiektatika konjenita saptandı (Resim 1). Diğer sistem muayenesinde bir özellik yoktu.
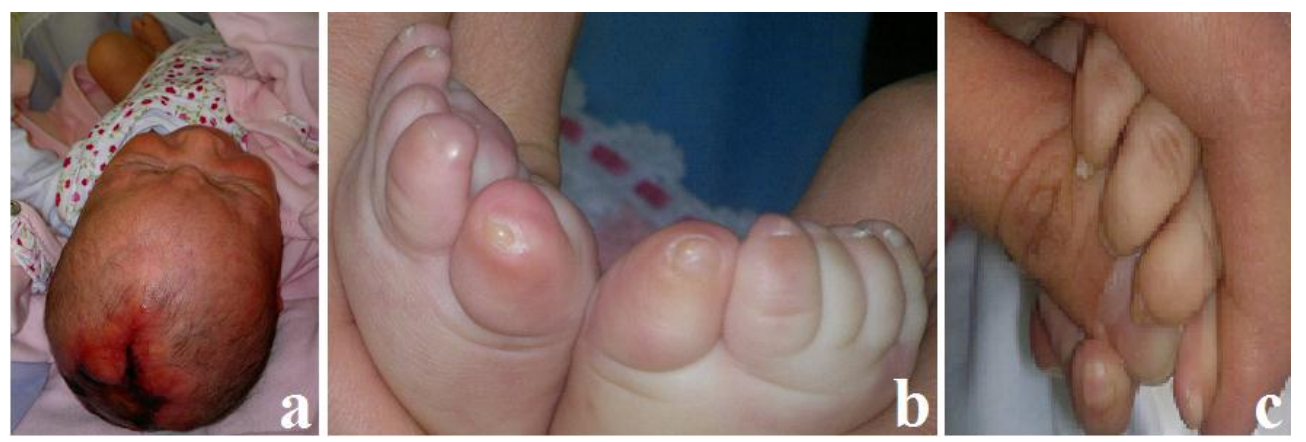

Resim 1a. Olgunun saçı derisinde aplazi kutis konjenita.1b-c El ve ayaklarda distal falanks ve tırnak hipoplazisi veya yokluğu.

Kan biyokimyası ve diğer kan ve idrar tetkikleri normal olarak sonuçlandı. Kromozom analizinde karyotipi normal bulundu. Ek anomaliler açısından yapılan radyolojik incelemelerinde (ekokardiyografi, transfontanel ultrasonografi, abdominal ultrasonografi) patolojik bulgu saptanmadi. Çekilen direkt ekstremite grafilerinde terminal falanks hipoplazisi veya yokluğu saptandı (Resim 2).

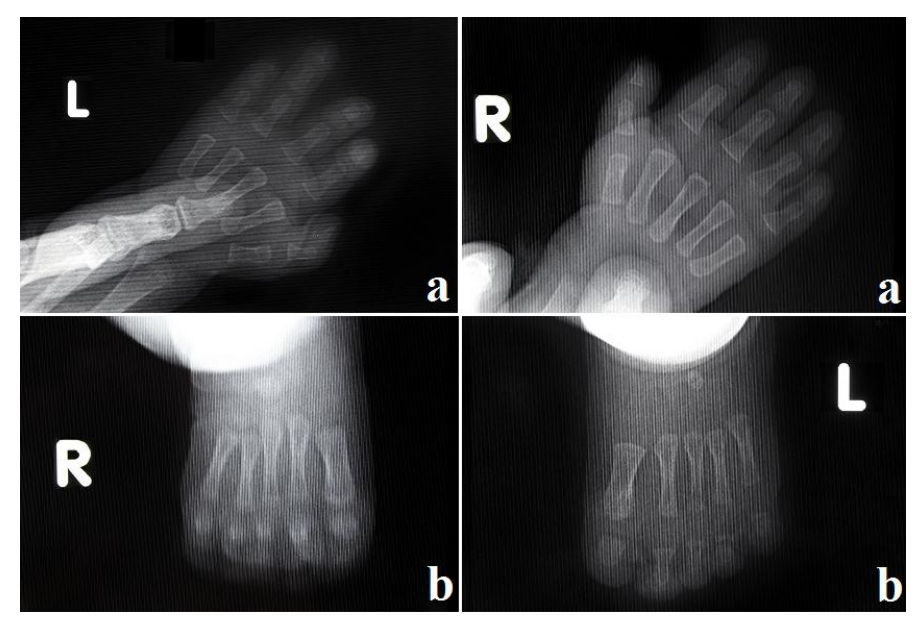

Resim 2a-b. El ve ayaklarda distal falanks yokluğu izlenmektedir. 
Kafa derisine lokal antibakteriyel pomatlarla günlük bakım yapıldı. Aileye gelişebilecek komplikasyonlar konusunda bilgi verildi. Postnatal 10. gün hasta taburcu edildi. Olgunun 9. ayında tartı: $7000 \mathrm{gr}$ (3-10 p), boy: $68 \mathrm{~cm}(25-50$ p), baş çevresi: $42,5 \mathrm{~cm}$ (3p) idi. Kafa derisinde, vertekste, yaklaşı 10x10 cm'lik alopesik bir alan vardı. Palpasyonda, bu bölgenin atrofik karakterli ve az gelişmiş olduğu görüldü (Resim 3). İlk 9 aylık izlemlerinde nöromotor gelişiminin yaşına uygun olduğu görüldü.

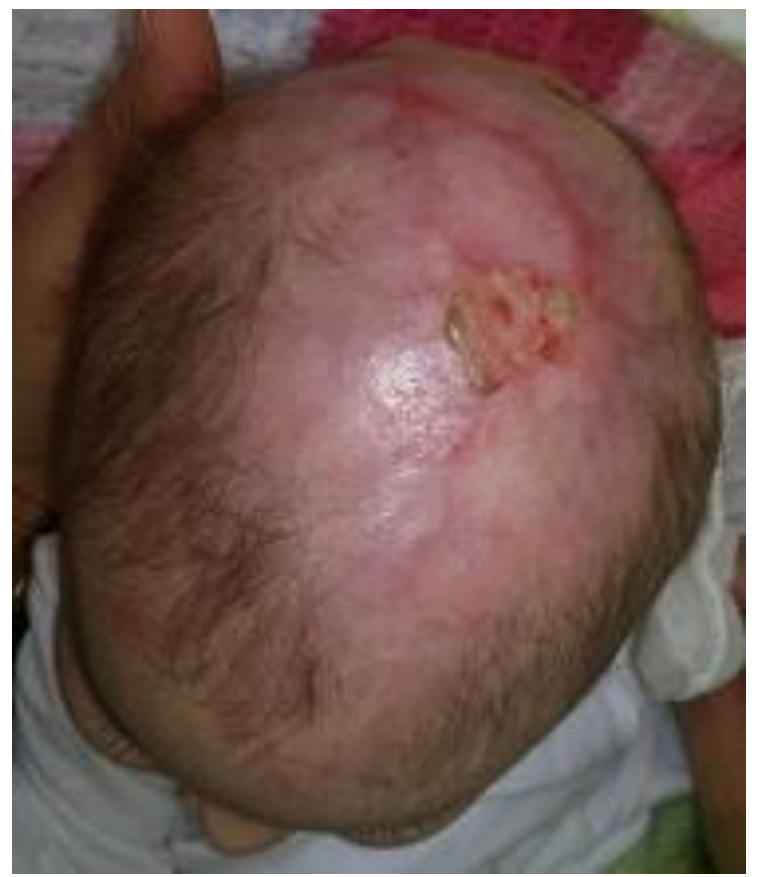

Resim 3. Olgu 9 aylıkken saçlı deri defektinin görünümü.

\section{Tartışma}

Adams Oliver Sendromu, aplasia kutis konjenita, transvers terminal ekstremite defektleri ve kutis marmorata telenjiektatika konjenita ile karakterize bir sendromdur [1, 4]. Sendrom ilk olarak 1945 yılında Adams ve Oliver Tarafından tanımlanmıştır [1]. Sendromun kalıtımı, ilk tanımlandığı ailede otozomal dominant olarak tanımlanmıştır. Daha sonra azalmış penetranslı otozomal dominant ve otozomal resesif formlar da bildirilmiştir [5-8]. Bunların dışında, vakaların çoğu sporadik olarak tanımlanmıştır. Ancak, genin penetrans göstermediği ailelerde olgular sporadik olmadığı halde sporadik düşünülebilir [9]. Olgumuzun anne ve babası akraba değildi ve ailesinde sendroma ait anomaliler bulunmadığından olgumuz sporadik olarak değerlendirildi. Ekstremite defektleri en sık gözlenen fizik bulgudur ve sıklıkla asimetriktir [9]. Tutulum brakidaktili, sindaktili, tırnak hipoplazisi, distal falanks agenezisinden, parmak, el, ayak ya da ekstremitenin tam yokluğuna kadar değişen şiddette görülebilmektedir [9, 10]. Skalp defektleri ikinci en s1k bulgudur [11]. Aplasia kutis konjenita sıklıkla vertekste bulunur ve genişlik ve derinliği değişkenlik gösterir. Saçlı deri lezyonlarının altında kafatası deformiteleri de görülebilmektedir [12]. Adams Oliver sendromlu olgularda, ensefalosel, mikrosefali, sol arteria serebri hipoplazisi, spastik hemipleji, kortikal displazi, pakigiri, hipoplastik korpus kallozum, parankimal kalsifikasyonlar, ventrikülomegali, serebral korteks displazisi, serebral damar anomalileri gibi çeşitli intrakranial anomaliler bildirilmiştir. Bunların sonucu olarak, bu olgularda epilepsi ve mental retardasyon sık görülmektedir [2]. Kardiyovasküler malformasyonlar, valvüler anomaliler, pulmoner vasküler malformasyonlar ve pulmoner hipertansiyonu içermektedir [13]. Olgumuzda, kardiyovasküler, gastrointestinal ve santral sinir sistemi anomalileri yoktu. Kutis marmorata telenjiektatika konjenita, gastrointestinal ve hepatik malformasyonlar, aksesuar meme başı, mikrooftalmi, herediter hemorajik telenjiektazi ve yarık dudak gibi 
sendromla ilişkili defektler görülebilmektedir [14]. Adams Oliver sendromunun genetik nedenlerini ortaya koymak için Verdyck (2006), etkilenmiş 10 bireyden oluşan bir ailede, MSX1, ALX4, CART1, P63, RUNX2, HOXD13 genlerini incelemiş ve mutasyon saptayamamışlardır [15]. Konjenital skalp defekti ve ekstremite anomalileri, kromozom $3 q 13$ bölgesinde haritalanmış ve rapor edilmiştir $[15,16]$. ARHGAP31, RBPJ ve DOCK6 genlerinde mutasyonlar bildirilmiştir [17-19]. Ayırıcı tanıda trizomi 13, amniyotik band sekans1, epidermolizis bülloza distrofika, saçlı deri defektiyle birlikte polidaktili ve ektrodaktili, izole aplazi kutis konjenita sayılmaktadır [3]. Olgumuzda normal karyotip saptanması ve klinik bulguların farklı olması nedeniyle diğer sendromlar düşünülmemiştir.

Adams Oliver sendromu, letal anomalilerle birliktelik gösterebilen, nadir görülen, bir çok organı ilgilendiren bir sendrom olduğundan olgumuz literatürle tartışılarak sunulmuştur.

\section{Kaynaklar}

1. Adams FH, Oliver CP. Hereditary deformities in man: due to arrested development. J Hered 1945; 36: 3-7.

2. McGoey RR, Lacassie Y. Adams-Oliver syndrome in siblings with central nervous system findings, epilepsy, and developmental delay: refining the features of a severe autosomal recessive variant. Am J Med Genet A 2008; 146A: 488-91.

3. Farrell SA, Warda LJ, LaFlair P, Szymonowicz W. Adams-Oliver syndrome: A case with juvenile chronic myelogenous leukemia and chylothorax. Am J Med Genet 1993; 47: 1175-9.

4. Mempel M, Abeck D, Lange I, Strom K, Caliebe A, Beham A, Kautza M, Worret WI, Neubauer BA, Ring J, Schröder H, Fölster-Holst R. The wide spectrum of clinical expression in Adams Oliver syndrome: a report of two cases. Br J Dermatol 1999; 140: 1157-60.

5. Küster W, Lenz W, Kääriäinen $H$, Majewski F. Congenital scalp defects with distal limb anomalies (Adams-Oliver syndrome): report of ten cases and review of the literature. Am J Med Genet 1988; 31: 99-115.

6. Koiffmann CP, Wajntal A, Huyke BJ, Castro RM. Congenital scalp skull defects with distal limb anomalies (Adams-Oliver syndrome--McKusick 10030): further suggestion of autosomal recessive inheritance. Am J Med Genet 1988; 29: 263-8.

7. Becker R, Kunze J, Horn D, Gasiorek-Wiens A, Entezami M, Rossi R, Guschmann M, Sarioglu N. Autosomal recessive type of Adams-Oliver syndrome: Prenatal diagnosis. Ultrasound Obstet Gynecol 2002; 20: 506-10.

8. Unay B, Sarici SU, Gül D, Akin R, Gökçay E. Adams-Oliver syndrome: Further evidence for autosomal recessive inheritance. Clin Dysmorphol 2001; 10: 223-5.

9. Whitley CB, Gorlin RJ. Adams-Oliver syndrome revisited. Am J Med Genet 1991; 40: 319-26.

10. Sankhyan N, Kaushal rk, Jaswal RS Adams-Oliver syndrome: a case with complete expression. J Dermatol 2006; 33: 435-6.

11. Narang T, Kanwar AJ, Dogra S. Adams-Oliver syndrome: a sporadic occurrence with minimal disease expression. Pediatr Dermatol 2008; 25: 115-6.

12. Verdyck P, Holder-Espinasse M, Hul WV, Wuyts W. Clinical and molecular analysis of nine families with Adams-Oliver syndrome. Eur J Hum Genet 2003; 11: 457-63.

13. Swartz EN, Sanatani S, Sandor GG, Schreiber RA. Vascular abnormalities in Adams-Oliver syndrome: cause or effect? Am J Med Genet 1999; 82: 49-52.

14. Seo JK, Kang JH, Lee HJ, Lee D, Sung HS, Hwang SW. A case of Adams-Oliver syndrome. Ann Dermatol 2010; 22: 96-8.

15. Verdyck P, Blaumeiser B, Holder-Espinasse M, Van Hul W, Wuyts W. AdamsOliver syndrome: clinical description of a four-generation family and exclusion of five candidate genes. Clin Genet 2006; 69: 86-92. 
16. Bonafede RP, Beighton P. Autosomal dominant inheritance of scalp defects with ectrodactyly. Am J Med Genet 1979; 3: 35-41.

17. Southgate L, Machado RD, Snape KM, Primeau M, Dafou D, Ruddy DM, Branney PA, Fisher M, Lee GJ, Simpson MA, He Y, Bradshaw TY, Blaumeiser B, Winship WS, Reardon W, Maher ER, FitzPatrick DR, Wuyts W, Zenker M, Lamarche-Vane N, Trembath RC. Gain-of-function mutations of ARHGAP31, a Cdc42/Rac1 GTPase regulator, cause syndromic cutis aplasia and limb anomalies. Am J Hum Genet 2011; 88: 574-85.

18. Hassed SJ, Wiley GB, Wang S, Lee JY, Li S, Xu W, Zhao ZJ, Mulvihill JJ, Robertson J, Warner J, Gaffney PM. RBPJ mutations identified in two families affected by Adams-Oliver syndrome. Am J Hum Genet 2012; 91: 391-5.

19. Shaheen R, Faqeih E, Sunker A, Morsy H, Al-Sheddi T, Shamseldin HE, Adly N, Hashem M, Alkuraya FS. Recessive mutations in DOCK6, encoding the guanidine nucleotide exchange factor DOCK6, lead to abnormal actin cytoskeleton organization and Adams-Oliver syndrome. Am J Hum Genet 2011; 89: 328-33. 